\title{
Chronic actinic dermatitis
}

\author{
Christina M. Huang, Yuka Asai MD MSc
}

Cite as: CMAJ 2018 March 12;190:E297. doi: 10.1503/cmaj.171111

A 60-year-old man presented to our dermatology clinic with a photodistributed, eczematous eruption of the face, neck and arms (Figure 1). He had red hair and blue eyes, and worked as a mechanic. He had a history of eczema, asthma and hayfever with allergies to grass, tree, ragweed and flower pollen. He had been prescribed topical desoximetasone, and oral diphenhydramine, cetirizine and prednisone, with little effect. His presentation, age, gender and history were suggestive of chronic actinic dermatitis.

The patient underwent patch testing, and he was positive to tixocortol pivalate (2+), relevant to his cortisone cream; decyl glucoside (3+), a preservative in his sunscreen; and bisphenol $A$ epoxy resin (3+), which was present in his workplace. Phototesting showed a minimal erythema dose of less than $5 \mathrm{~J} / \mathrm{cm}^{2}$ to ultraviolet $A$ and less than $0.05 \mathrm{~J} / \mathrm{cm}^{2}$ to broadband ultraviolet $\mathrm{B}$. In the clinic where testing was completed, these scores were considered low for his skin type (Fitzpatrick skin type 3 ) and suggested photosensitivity to both ultraviolet $A$ (which can penetrate window glass) and $B$. The result of a subsequent photopatch test using ultraviolet $A\left(\right.$ at $3 \mathrm{~J} / \mathrm{cm}^{2}$ ) was negative. He also had a skin biopsy to rule out cutaneous T-cell lymphoma. He was diagnosed with chronic actinic dermatitis.

In addition to strict sun avoidance and photoprotective garments (Appendix 1, available at www.cmaj.ca/lookup/suppl/ doi:10.1503/cmaj.171111/-/DC1), the patient failed or was unable to tolerate topical therapies and several steroid-sparing agents (acitretin, cyclosporine, methotrexate, azathioprine). He required additional prednisone for flares of his condition. The severity of his disease led him to quit his job. To prevent exacerbations, he stopped pastimes such as biking, and limited his daytime activities, leading to social isolation. After multiple failures of therapy well described in patients with chronic actinic dermatitis - the use of mycophenolic acid (180 mg taken orally three times daily) and prednisone, along with strict sun avoidance and protective garments, eventually allowed him to control his condition enough to resume daily activities of living. His head covering, however, resulted in a publicized misunderstanding with the police. ${ }^{1}$

Chronic actinic dermatitis is an immune-mediated reaction to sun or artificial light, often accompanied by contact allergies. ${ }^{2}$ It is uncommon but may be underrecognized; it has been reported in the United States, Europe, Asia and Africa. It primarily affects men older than 50 years and is characterized by pruritic eczematous and lichenified plaques on sun-exposed areas, with notable sparing of skin folds, including submental chin, retroauricular areas and nasolabial folds. ${ }^{2}$ Careful history, examination and workup is essential, because many conditions may mimic chronic actinic dermatitis, including drug eruption, allergic or photoallergic contact dermatitis, cutaneous T-cell lymphoma and connective tissue diseases. ${ }^{2}$ In addition to itchy and painful eruptions and the adverse effects of treatment, light-sensitive disorders can result in social isolation, loss of work, decreased self-esteem and social stigma.

\section{References}

1. McEwen T. Port Hope Police takedown of man in mask deemed misunderstanding in Northumberland. Northumberland News [Cobourg (ON)] 2016 Aug. 11. Available: www.northumberlandnews.com/news-story/6805571-port-hope-police-takedown -of-man-in-mask-deemed-misunderstanding-in-northumberland/ (accessed 2017 Sept. 10).

2. Paek SY, Lim HW. Chronic actinic dermatitis. Dermatol Clin 2014;32:355-61.

\section{Competing interests: None declared.}

This article has been peer reviewed.

The authors have obtained patient consent.

Affiliations: School of Medicine (Huang); Division of Dermatology (Asai), Department of Medicine, Queen's University, Kingston, Ont.

Acknowledgements: The authors thank Drs. M. Pratt and S. Glassman for their help with patch- and phototesting of this case.

Correspondence to: Yuka Asai, yuka.asai@queensu.ca 